\title{
PATRIMÔNIO GEOMORFOLÓGICO NA PORÇÃO LESTE DO ESTADO DO TOCANTINS - REGIÃO DO JALAPÃO
}

\author{
Sandro Sidnei Vargas de Cristo $^{1}$, Luis Eduardo de Souza Robaina ${ }^{2} \&$ Fernando de Morais ${ }^{1}$ \\ 1-Universidade Federal do Tocantins (UFT).sidneicristo@uft.edu.br; morais@uft.edu.br \\ 2-Universidade Federal de Santa Maria (UFSM). lesrobaina@yahoo.com.br
}

\begin{abstract}
RESUMO: A região do Jalapão situada na porção central do Brasil é constituída geologicamente por embasamento cristalino, bacias sedimentares do Parnaíba e Sanfranciscana, recobertas por depósitos recentes, que sobrepõem os demais substratos. O patrimônio geomorfológico da região constitui-se de uma ampla variedade de feições e processos associados, às quais se atribui alto valor ecológicoambiental, porém com pouco detalhamento que demonstre sua origem, formação,desenvolvimento e importância. Neste sentido, o presente trabalho consiste numa apresentação, descrição e analise de algumas feições geomorfológicas que se destacam na porção leste do Estado do Tocantins, enfatizando aspectos morfogenéticos, morfoestruturais e morfométricos. Entre as feições estão os relevos residuais, cânions, cavernas, dunas e surgências de água subterrânea (localmente conhecidas como fervedouros). No tocante aos relevos residuais, destacam-se as Serra do Espírito Santo, que serve de área fonte para a formação das Dunas do Jalapão. As cavernas são de litologias variadas com predomínio dos carbonatos do Grupo Bambuí, que hospedam as feições mais representativas do relevo cárstico na região e, minoritariamente, os arenitos do Grupo Urucuia, que também possui cavidades de dimensões menos expressivas. Os fervedouros são pontos de exfiltração de águas advindas nos aquíferos profundos e que por descontinuidades estruturais afloram quase sempre associados às zonas de veredas. Esse conjunto de feições atribui ao Jalapão grande potencial ainda pouco explorado no viés geológico, geomorfológico e ambiental.
\end{abstract}

Palavras-chave: patrimônio geomorfológico; Jalapão; cânion; caverna; fervedouro.

ABSTRACT: GEOMORPHOLOGICAL HERITAGE IN THE EASTERN PORTION OF THE STATE OF TOCANTINS - REGION JALAPÃO. The Jalapão region, located in the central part of Brazil consists geologically of crystalline basement and sedimentary basins as Parnaíba and Sanfranciscana, covered by recent deposits, which overlap the other substrates. The geomorphologic heritage of the region is made up of a wide variety of features and associated processes, which can have a high ecologic-environmental value, besides the lack of details to show its origin, formation, development and significance. Having pointed some important comments about Jalapão, the present work aims at presenting the description and the analysis of some geomorphologic features that is very important in the eastern portion of the State of Tocantins, emphasizing morphogenetic, morphostructural and morphometric data. Among the features we are going to talk about, there are the residual relief, canyons, caves, dunes and groundwater resurgences (fervedouros). Concerning the residual relief, there are the Serra do Espírito Santo, which serves as the source area for the formation of Jalapão dunes. The caves comes from the predominant lithologies of Bambui Group carbonates, which hosts the most representative features of the karst region and, lastly from the minority group, the sandstones Urucuia Group, which also owns cavities of dimensions less expressive. The fervedouros are exfiltration waters resulting from deep aquifers and by structural discontinuities that arise almost always associated to areas of swampy plains between rivers and hills. This combination of features gives the Jalapão a great potential not yet explored on the geologic, geomorphologic and environmental bias.

Keywords: geomorphologic heritage; Jalapão; canyon; cave; fervedouro.

\section{INTRODUÇÃO}

A abordagem das questões relacionadas a patrimônios naturais, como geológicos e geomorfológicos, tem ganhado um espaço significativo nas discussões mundiais, visto que são diversos os países que se manifestam em sua defesa e significado ambiental, turístico e cultural.

No Brasil, a preocupação com esta questão também começa a tomar maior espaço nas discussões com desenvolvimentos de trabalhos de pesquisa, como pode-se perceber com a realização de eventos e publicações na área. Isto demonstra, além da preocupação com a busca de melhor conhecimento sobre o patrimônio nacional, bem como em termos de seu potencial.

De maneira geral a abordagem do patrimônio natural brasileiro, com ênfase aos aspectos geológicos e geomorfológicos, demonstra cada vez mais, sua importância na preservação ambiental, aumentando o interesse de pesquisadores pela temática. Além disso, os locais com patrimônio natural são muitas vezes os que apresentam fragilidades ambientais naturais de degradação ou que estão sob forte pressão humana.

Assim, definiu-se como área de pesquisa a porção leste do Estado do Tocantins, por ser um local que apresenta importância relevante na preservação de determinadas feições geomorfológicas, além dos demais aspectos da geodiversidade, tais como os aspectos geológicos, pedológicos e geomorfológicos que demonstram seu potencial.

Este estudo mostra-se relevante, pelo fato do Jalapão, especialmente para o Estado do Tocantins (TO), estar sofrendo impactos sociais e ambientais significativos, ocasionados pela implementação de grandes projetos de desenvolvimento e de expansão agrícola que se tornaram uma ameaça para esta região,que representa uma importante parcela do Bioma Cerrado e da região do divisor de águas das bacias dos rios Tocantins e São Francisco, umas das áreas de deposição sedimentar mais bela e frágil do país com feições geomorfológicas únicas.

Vale ressaltar que a região do Jalapão abriga remanescentes do Cerrado, incluindo Unidades de 
Conservação da Natureza deste domínio geográfico (Klinc \& Machado 2005), o que a coloca as mais importantes regiões naturais do Brasil, porquanto abriguem as últimas grandes extensões da única área de Savana considerada como um hotspot ${ }^{1}$ global de biodiversidade (Myers et al. 2000).

$\mathrm{Na}$ medida em que os problemas ambientais se multiplicam, propõe-se contribuir na busca de alternativas que visem ampliar o conhecimento sobre a importância da área de pesquisa com suas limitações e potencialidades ambientais, dando ênfase à questão do patrimônio geomorfológico, para "melhorar" a relação entre o ser humano e a qualidade ambiental local.

\section{2. Área de Estudo}

A área considerada no presente trabalho abrange a porção leste do Estado do Tocantins, integra a região conhecida como Jalapão, e limita-se de maneira geral com os Estados da Bahia, Piauí e Maranhão (Fig. 1).

Conforme a Seplan (2012), a área em questão integra as Regiões Político-Administrativas de Novo Acordo e Dianópolis, apresentando as seguintes características:

A rede hidrográfica faz parte das nascentes de três das principais bacias hidrográficas do Estado do Tocantins que drenam a região sudeste e abastecem o Rio Tocantins, sendo estas as do Rio Sono, do Rio das Balsas e do Rio Manuel Alves; além das nascentes do Rio Preto no Estado da Bahia.

O ambiente geológico caracterizado pela presença de Bacias Sedimentares e Depósitos Sedimentares Inconsolidados com predomínio de Neossolos Quartzarenicos e, secundariamente, Latossolos.

O clima predominante é úmido subúmido com moderada deficiência hídrica no inverno, evapotranspiração potencial média anual de $1.500 \mathrm{~mm}$, distribuindo-se no verão em torno de 420 $\mathrm{mm}$ ao longo dos três meses consecutivos com temperatura mais elevada.

A precipitação média anual fica entre os $1.300 \mathrm{~mm}$ a $1.500 \mathrm{~mm}$ e a temperatura média anual do ar fica em torno dos $25^{\circ}$ a $26^{\circ} \mathrm{C}$.

A altitude varia entre $200 \mathrm{~m}$ a $900 \mathrm{~m}$, desde as porções mais baixas até as mais elevadas e a hidrogeologia apresenta o aquífero Urucuia como unidade mais expressiva.

Quanto à vegetação, os subtipos de formações savânicas caracterizam-se por uma camada rasteira predominantemente herbácea e por uma cobertura lenhosa, que varia de 5 a $20 \%$ em áreas de cerrado ralo (savana parque), situa-se entre 20 e $50 \%$ em

${ }^{1}$ Hotspot: toda área prioritária para conservação, isto é de biodiversidade e ameaçada no mais alto grau (Myers et al., 2000) cerrado típico (savana arborizada), e vai de 50 a $70 \%$ em cerrado denso (savana arborizada).

O cerrado rupestre (savana arborizada) desenvolve-se sobre afloramento rochoso,enquanto que nas planícies inundáveis, desenvolve-se a savana parque;as veredas são formações savânicas que ocupam as cabeceiras de drenagens e o cerradão (savana florestada) é considerado uma formação florestal.

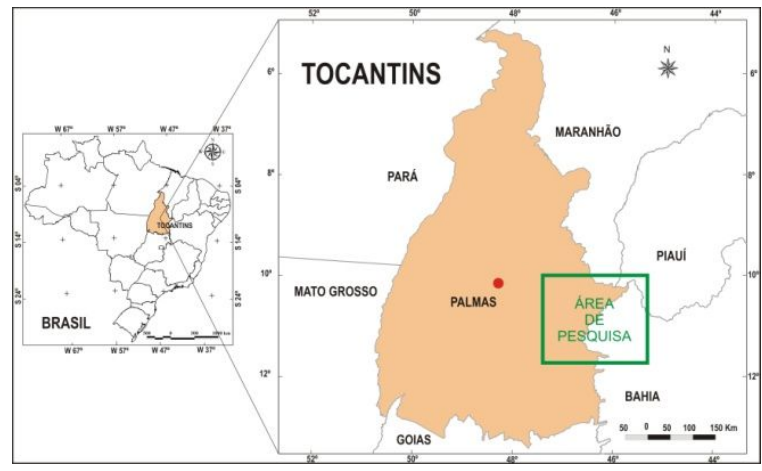

Figura 1 - Mapa de localização da área de pesquisa

\section{PATRIMÔNIO GEOMORFOLÓGICO DA REGIÃO DO JALAPÃO}

Quanto ao patrimônio geomorfológico da região do Jalapão, podem ser observadas diversas feições geomorfológicas, entre estas pode-se destacar, os relevos residuais como a Serra do Espírito Santo, cânions como o da Garganta, fervedouros como o dos Buritis e cavernas como a do japonês (Figura 2).

As feições de Relevos Residuais são predominantemente tabulares, decorrentes da erosão regressiva ou recuo das escarpas do relevo sedimentar, como as Serras da Muriçoca, a Serra Geral e da Chapada das Mangabeiras.

A ação de processos erosivos que incidem sobre as rochas locais fragmenta as porções mais friáveis (erosão diferencial), ocasionando o transporte dos sedimentos, restando apenas às porções mais resistentes que dão origem às formas específicas.

Estas feições são formadas por rochas sedimentares estratificadas, com topos planos e encostas escarpadas, características de relevos tabulares que se apresentam no terreno como resquícios de rochas cimentadas pela sílica e óxido de ferro, o que permite a manutenção parcial de suas estruturas.

De maneira geral as feições apresentam, na porção superior, camadas de rochas areníticas estratificadas com coloração esbranquiçada, como produto da cimentação silicosa, enquanto que as camadas inferiores são compostas por rochas areníticas estratificadas de coloração avermelhada pela pigmentação de óxido de ferro. Entre estas feições pode ser destacadas a Serra do Espírito Santo (Figura 3). 


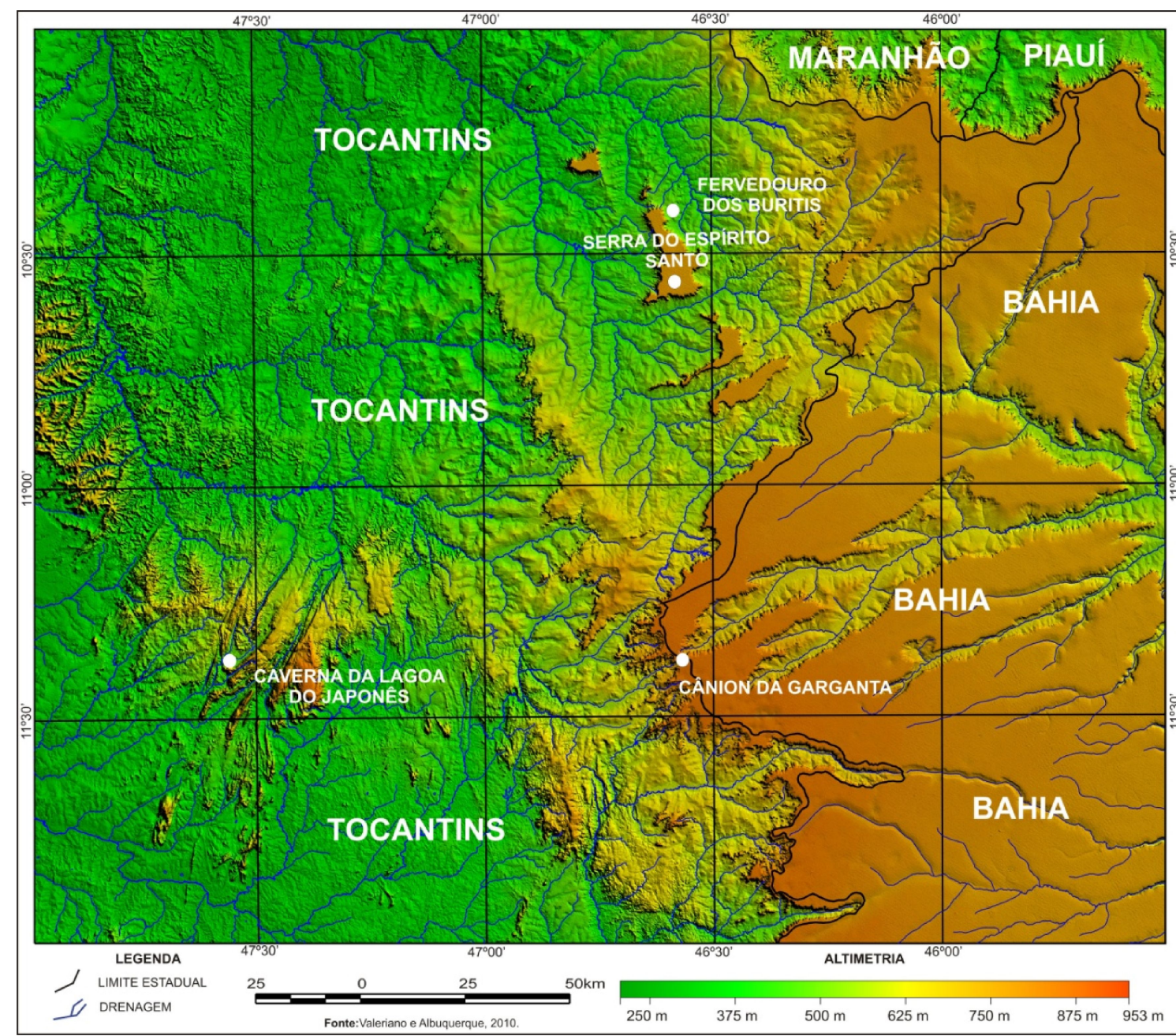

Figura 2 - Feições Geomorfológicas em destaque na área de pesquisa

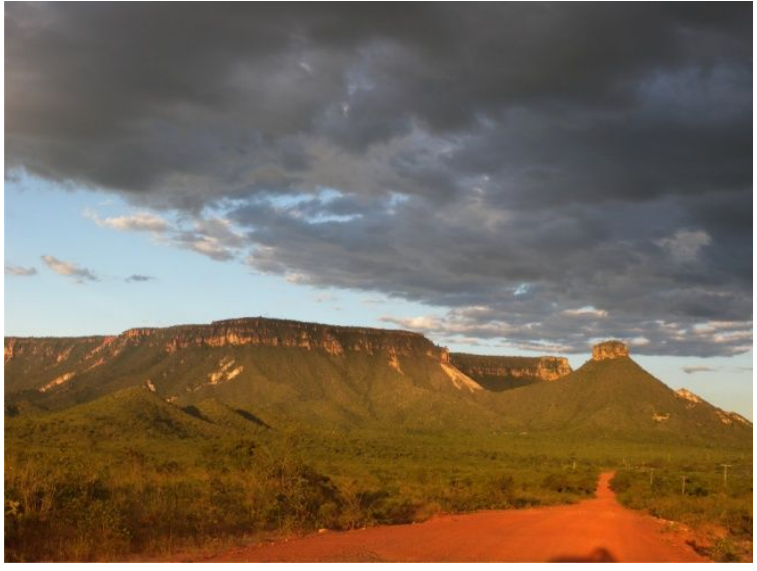

Figura 3-Relevo Residual representado pela Serra do Espírito Santo com topo plano e encostas escarpadas. Fotografia: Cristo, maio de 2011.

Os Cânions se caracterizam pela existência de significativos vales encaixados cuja drenagem se aprofunda verticalmente escavando o substrato geológico, formando patamares laterais (superfícies de aplanamento exumadas) com alta inclinação e fundos chatos.

Nestas feições, as rotas preferenciais dos fluxos superficiais ou subsuperficiais definem os mecanismos erosivos e deposicionais preponderantes e resultam da interação de diversos fatores bióticos (flora e fauna), abióticos (clima, rocha, solo e posição topográfica) e antrópico (uso do solo), que compõem o respectivo ambiente de drenagem (Coelho Netto 1995).

De modo geral, considera-se que as feições em questão resultam da definição preponderante de rotas preferenciais dos fluxos superficiais e subsuperficias que atuam sobre a cobertura vegetal, além das características geológico-geomorfológicas, proporcionando o entalhamento dos canais fluviais.

Os Cânions da área de pesquisa ocorrem em áreas junto às cabeceiras de drenagens, onde estão as maiores elevações do terreno, que por características próprias, aumentam a velocidade de escoamento e consequentemente o seu poder erosivo. Entre estas feições, pode ser destacado o Cânion da Garganta (Figura 4).

Os fervedouros são feições geomorfológicas que, de maneira geral, se caracterizam pela presença de poços de águas cristalinas com formas circulares, diâmetros variados, originados basicamente pelo 
afloramento ascendente do aquífero confinado (artesianismo).

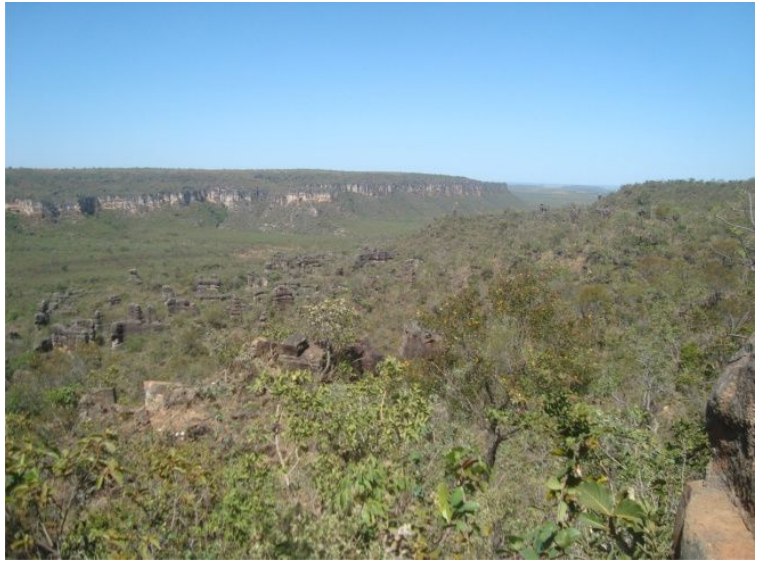

Figura 4 - Cânion da Garganta com a erosão vertical aprofundando o canal de drenagem, escavando o substrato geológico. Fotografia: Cristo, novembro de 2012.

De maneira específica, estas feições são formadas pela exposição pontual de água subterrânea que exerce uma forte pressão no sentido vertical na busca do seu equilíbrio hidrostático, o que gera a suspensão de sedimentos, objetos ou pessoas que entram nele, propiciando "sensação de flutuação".

Também se destaca nesta feição, as águas transparentes, a concentração de areia branca muito fina, vegetação caracterizada por espécies do Cerrado e algumas cultivadas na região. Entre estas feições pode ser destacado o Fervedouro dos Buritis (Fig. 5)

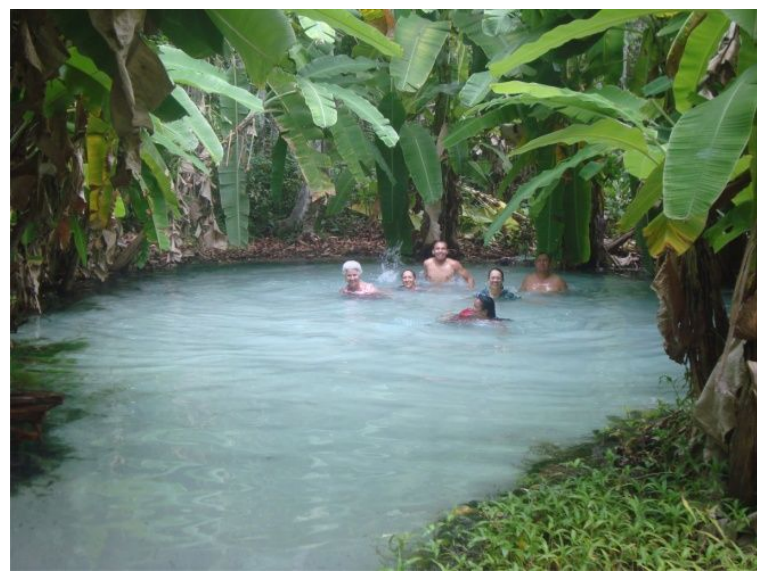

Figura 5 - Fervedouro dos Buritis com forma circular, água cristalina e vegetação cultivada no entorno. Fotografia: Cristo, novembro de 2012

As cavernas são feições geomorfológicas que ocorrem pela presença de formas cobertas e em processo de exumação, as quais estão associadas à exposição do Grupo Bambuí, condicionada principalmente pelo recuo paralelo das vertentes escarpadas das rochas areníticas sobrejacentes.
As cavernas em rochas carbonáticas que mais se destacam pela sua beleza cênica estão situadas no vale do Rio Palmeiras, entre os municípios de Dianópolis e Novo Jardim.

Nas proximidades da cidade de Pindorama do Tocantins, a caverna da Lagoa do Japonês (Figura 6) chama atenção pelas suas características geológicogeomorfológicas, estando esta cavidade condicionada por dissolução do calcário situado na porção interna de uma grande dobra sinclinal deitada.

Ademais, vários espeleotemas que denotam mudanças no nível de base local contribuem para elevação do seu valor para a compreensão da evolução do relevo regional.

No tocante às cavidades em arenitos mais significativas estão nas proximidades das cidades de Novo Acordo (Caverna do Morro do Homem) e Ponte Alta do Tocantins (Abrigo da Água Limpa, Sumidouro da Aroeira, Ruínas e Pedra Furada).

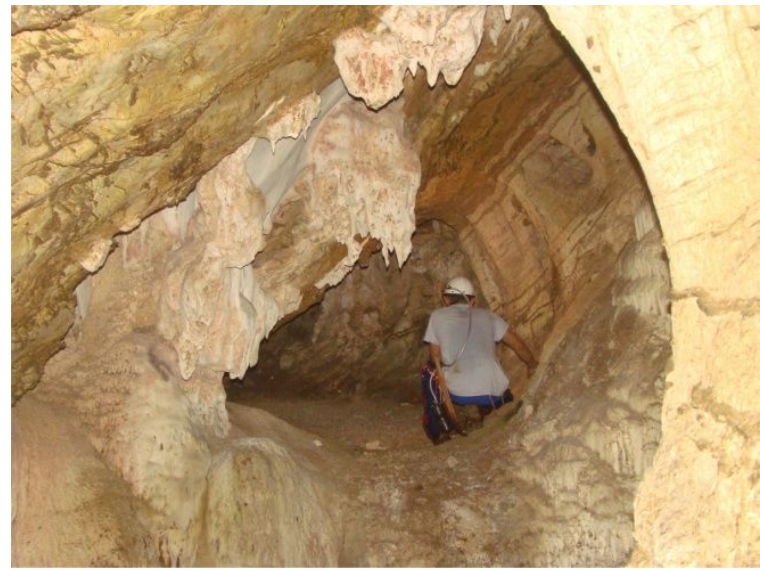

Figura 6 - Aspectos internos da caverna da Lagoa do Japonês. Fotografia: Morais, setembro de 2010.

\section{CONCLUSÕES}

A geomorfologia, que proporciona os diferentes modelados de relevo e, consequentemente, forja o patrimônio geomorfológico da área de pesquisa, é fator elementar na sua caracterização, mormente devido ao predomínio de relevos sedimentares resultantes de processos que representam a dinâmica de transformação que ali se dá.

O patrimônio geomorfológico representado por Relevos Sedimentares, Cânions, Fervedouros e Cavernas, reforçam a necessidade da incorporação deste patrimônio enquanto elemento a ser preservado e demonstra sua importância, na incorporação as atividades turísticas da região do Jalapão.

As características ímpares de algumas feições geomorfológicas já mencionadas na área de pesquisa evidenciam a existência de fenômenos 
naturais considerados raros relacionados ao seu patrimônio geomorfológico, como o Fervedouro com área de "surgência de água subterrânea" exercendo pressão em direção à superfície proporcionando a "sensação de flutuação".

Ademais, a composição variada do relevo regional eleva seu potencial para o desenvolvimento de atividades ligadas ao ecoturismo e turismo de aventura que, via de regra, compõem atividades realizadas em geoparques. Assim, sugere-se uma discussão acerca da possibilidade de criação de um geoparque como valorização do patrimônio natural da região do Jalapão.

\section{REFERÊNCIAS BIBLIOGRÁFICAS}

Coelho Netto A.L. 1995. Hidrologia de Encosta na Interface com a Geomorfologia. In: Guerra A.T. \& Cunha S.B.T. (orgs.) Geomorfologia: Uma atualização de bases e conceitos. Bertrand Brasil, Rio de Janeiro, 2ed. p.: 93-148
Klinc C.A. \& Machado R.B. 2005. Conservation of the do Brazilian Cerrado. Malden: Conservation Biology, v.19.

Myers N., Mittermeier R.A., Mittermeier C.G., Fonseca G.A.B., Kent J. 2000. Biodiversity hotspots for conservation priorities. Nature, 403:853-858.

SEPLAN - Secretaria do Planejamento e da Modernização Pública. 2012. Atlas do Tocantins: Subsídios ao Planejamento da Gestão Territorial, Superintendência de Pesquisa e Zoneamento Ecológico-Econômico, Diretoria de Zoneamento Ecológico-Econômico - DZE, Palmas, 6 ed. 80 p.

Valeriano M. M. \& Albuquerque, P.C.G. 2010. TOPODATA: Processamento dos dados SRTM. São José dos Campos - SP: INPE. Disponível

em http://www.dsr.inpe.br/topodata/documentos.php. Acessado em: 25 jan 2010

Contribuição ao II Simpósio Brasileiro de Patrimônio Geológico I Workshop Brasileiro de Patrimônio Geológico Construído 24 a 28 de setembro de 2013, Ouro Preto, MG. 